\title{
ОПРЕДЕЛЕНИЕ ЗАТРАТ ЭНЕРГИИ ПРИ ОБРАЗОВАНИИ НОВОЙ ПОВЕРХНОСТИ В ПРОЦЕССЕ УЛЬТРАЗВУКОВОГО ИЗМЕЛЬЧЕНИЯ ШПИНАТНОГО ЛИСТА
}

\author{
Z.M. Arabova, A.Kh.-Kh. Nugmanov, \\ I.Yu. Aleksanian, V.N. Lysova, V.E. Polikarpova
}

\section{DETERMINATION OF ENERGY CONSUMPTION DURING THE FORMATION OF A NEW SURFACE IN THE PROCESS OF ULTRASONIC GRINDING OF SPINACH LEAF}

Арабова Зарема Михайловна - асп. каф. технологических машин и оборудования Астраханского государственного технического университета, г. Астрахань. E-mail: albert909@yandex.ru

Нугманов Альберт Хамед-Харисович д-р техн. наук, проф. каф. технологических машин и оборудования Астраханского государственного технического университета, г. Астрахань.

E-mail: albert909@yandex.ru

Алексанян Игорь Юрьевич - д-р техн. наук, проф. каф. технологических машин и оборудования Астраханского государственного технического университета, г. Астрахань.

E-mail: albert909@yandex.ru

Лысова Вера Николаевна - канд. техн. наук, доц. каф. технологических машин и оборудования Астраханского государственного технического университета, г. Астрахань.

E-mail: albert909@yandex.ru

Поликарпова Виолетта Эдуардовна - асп. каф. технологических машин и оборудования Астраханского государственного технического университета, г. Астрахань.

E-mail: albert909@yandex.ru

В данной статье рассмотрен важный этап подготовки листьев шпината к экстрагированию хлоросрилла, а именно его предварительное кратковременное замачивание 6 эмульсии вода/органический реагент при ультразвуковом воздействии. Путем визуальной и математической оценки микрофотографрий до и после измельчения подтверждена иелесообразность проведения данной физикохимической обработки листьев шпината. Комплексная оценка эфффективности проведения данной операщии связана с дополнительным измельчением сырья в поле ультразвука,
Arabova Zarema Mikhaylovna - Post-Graduate Student, Chair of Technological Machines and Equipment, Astrakhan State Technical University, Astrakhan. E-mail: albert909@yandex.ru

Nugmanov Albert Khamed-Kharisovich - Dr. Techn. Sci., Prof., Chair of Technological Machines and Equipment, Astrakhan State Technical University, Astrakhan.

E-mail: albert909@yandex.ru

Aleksanyan Igor Yuryevich - Dr. Techn. Sci., Prof., Chair of Technological Machines and Equipment, Astrakhan State Technical University, Astrakhan.

E-mail: albert909@yandex.ru

Lysova Vera Nikolaevna - Cand. Techn. Sci., Assoc. Prof., Chair of Technological Machines and Equipment, Astrakhan State Technical University, Astrakhan.

E-mail: albert909@yandex.ru

Polikarpova Violetta Eduardovna - PostGraduate Student, Chair of Technological Machines and Equipment, Astrakhan State Technical University, Astrakhan.

E-mail: albert909@yandex.ru

для которого целесообразно определить степень однородности дисперсного состава взвешенных частиц и выявить технологические подходы к ее повышению, то есть определить затраты энергии на образование вновь образованной поверхности. Энергозатраты при операции измельчения материала определяются в основном его физикохимическими характеристиками, обусловленными напряжением упругих деформаций, а также модулем упругости. Для объектов одного химического состава эти параметры могут отличаться, что определяется $u x$ 
структурным различием и варьированием элементного и компонентного соотношения, вследствие чего данные показатели находятся прямыми или косвенными методами для конкретного продукта. Выбор в качестве исходного материала листьев шпината для получения натурального красителя на основе хлорофиллов обусловлен тем, что данный овощ является пищевым сырьем, богатым на этот пигмент, и хорошим источником различных по своим фуннкциональным свойствам биологически активных веществ. Измельченный шпинатный пигментный премикс используют для обогащения продукции общественного, в частности, диетического, специализированного и лечебно-профилактического питания. Принимаем, что энергия, расходуемая на измельчение продукта, будет пропорииональна образуемой при нем дополнительной поверхности, то есть для создания единицы дополнительной поверхности необходимо произвести определенную удельную работу. Авторы определяли ее величину эмпирически, полагая, что она является обобщенным параметром, обусловленным характеристиками измельчаемого объекта. В материалах статьи приведен метод эмпирического расчета величины удельной работы, реализованный на примере листьев шпината.

Ключевые слова: шпинат, хлорофилл, измельчение ультразвуком, дисперсный анализ, работа на измельчение, ультразвуковые установки.

This article discusses an important stage in the preparation of spinach leaves for the extraction of chlorophyll, namely, its preliminary short-term soaking in an emulsion of water / organic reagent under ultrasonic treatment. By visual and mathematical evaluation of microphotographs before and after grinding, the feasibility of this physico-chemical treatment of spinach leaves was confirmed. A comprehensive assessment of the effectiveness of this operation is associated with additional grinding of raw materials in the ultrasound field, for which it is advisable to determine the degree of homogeneity of the dispersed composition of suspended particles and to identify technological approaches to its increase, that is, to determine the energy costs for the formation of a newly formed surface. The ener- gy consumption during the grinding operation of the material is mainly due to its physico-chemical characteristics, due to the stress of elastic deformation, as well as the elastic modulus. For objects of the same chemical composition, these parameters may differ, which is determined by their structural difference and variation in elemental and component and ratios, as a result of which these indicators are found by direct or indirect methods for a particular product. The choice of spinach leaves as a starting material for obtaining a natural dye based on chlorophylls is due to the fact that this vegetable is a food raw material rich in this pigment and a good source of biologically active substances of various functional properties. Shredded spinach pigment premix is used to enrich the products of public, in particular, dietary, specialized and medicalpreventive nutrition. We accept that the energy spent on grinding the product will be proportional to the additional surface formed during it, that is, to create a unit of additional surface, it is necessary to carry out a certain specific work. The authors determined its value empirically, assuming that it is a generalized parameter due to the characteristics of the ground object. The article presents a method of empirical calculation of the magnitude of the specific work, implemented on the example of spinach leaves.

Keywords: spinach, chlorophyll, ultrasonic grinding, dispersion analysis, grinding work, ultrasonic plants.

Введение. Подготовка сырья к экстракции это важная ступень в экстракционной технологии, так как подготовленный материал должен иметь заданные свойства, для приобретения которых применяются традиционные, но сравнительно малоэффрективные способы. Ожидаемый результат в значительной степени будет определяться режимами проведения подготовительных операций и их взаимосвязанностью для осуществления непрерывного технологического потока.

Цель исследования. Разработка рационального технологического потока подготовки листьев шпината к экстрагированию хлорофилла.

Задачи: на основе анализа достоинств и недостатков существующих технологий получения хлорофилла предложить рациональную схему 
подготовки сырья к экстрагированию; выявить влияющие на протекание операций подготовки сырья режимные параметры; разработать методы их определения; определить рациональные величины режимных параметров; предложить практические рекомендации по аппаратурному оформлению технологического потока и реализации результатов исследования.

Для решения задачи более полного извлечения хлорофилла из измельченных листьев шпината их целесообразно подвергнуть предварительному кратковременному замачиванию в эмульсии (вода с органическим реагентом) [1] с использованием ультразвукового воздействия. С целью получения дополнительной эффективности в последующих операциях, в нашем случае в экстрагировании хлорофиллов, необходимо повысить однородность сырья по размерам,

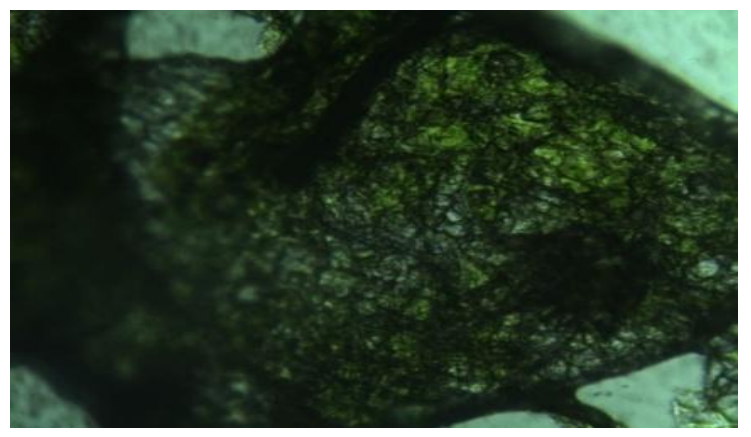
a

Puc. 1. Микрофотографрия частички до

Для комплексной оценки эффрективности проведения операций замачивания и ультразвукового измельчения целесообразно определить степень однородности дисперсного состава взвешенных частиц и выявить технологические подходы к ее повышению, что приведет к интенсификации и повышению степени извлечения ценных компонентов из шпината.

Материалы и методы. Выбор в качестве исходного материала листьев шпината для получения натурального красителя на основе хлорофриллов обусловлен тем, что данный овощ является пищевым сырьем, богатым на этот пигмент, и источником биологически активных веществ [2], которые в листве шпината находятся в соединении с белками, и такой обычный для растений комплекс имеет название хлорогибин [3]. Хлорофиллы растворимы в органических растворителях, но растворы их нестойкие, поэтому после отгонки экстрагента хлорофилл массе и другим качественным показателям непосредственно в процессе его фризикохимической обработки органическими реагентами.

На микрофротографияях частичек растительного сырья до и после процесса замачивания в специально подготовленной эмульсии (вода и стеароилполилактат натрия (E-481) или вода и янтол) (рис. 1) отчетливо видна эфффективность проведения данной физико-химической обработки. Если на первом микроснимке (рис. 1, а) целевой компонент, имеющий зеленую окраску, собран в агломераты, то на втором снимке (рис. 1, б), уже после проведения процесса при ультразвуковом воздействии, наблюдается их разбивка на более мелкие части, что подтверждает целесообразность проведения данной фризико-химической обработки листьев шпината.

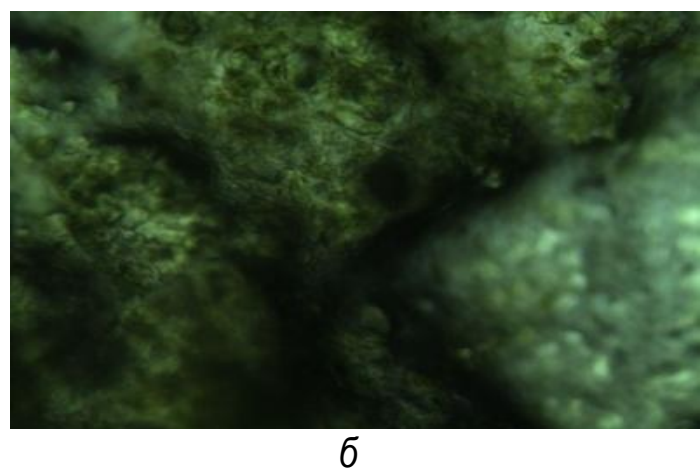

(а) и после (б) процесса замачивания

целесообразно растворить в жирах, что увеличивает их сохранность [4]. Кроме того, шпинат холодостоек, что важно для северных территорий, и имеет большую урожайность $[1,5]$. Данный пигментный премикс используют для обогащения продукции общественного, в частности диетического, специализированного и лечебнопрофилактического питания.

При операции замачивания измельченных листьев получается водоэмульсионная суспензия, в которой трехмерная неоднородность в виде взвеси в общем случае может рассматриваться как частица. Как правило, этот термин используется по отношению к твердым веществам, взвешенным в жидкости, или каплям, диспергированным в эмульсии.

Используя ISO9276-1: 1998, условно можно принять за размер любой частицы диаметр шара (ссрерический эквивалентный диаметр) с идентичными фризическими характеристиками. 
Данная сфрера обладает лишь одной величиной диаметра [6].

Под микроскопом частица представляется в плоской проекции, что обусловливает возможность варьирования диаметра частицы (рис. 1). Следует учесть, что каждый подход к определению размерного параметра частицы опирается на определение разных показателей (наибольшая или наименьшая длина, объем, поверхностная площадь и др.). В итоге результаты не являются однозначными и варьируются при смене методики определения. С целью оценки размерного распределения частиц целесообразно применять методики, дающие возможность статистической обработки результатов замеров для множества частиц, обычно более двухсот, или взять за основу массу фрракций. К таким методикам можно причислить замеры посредством оптических и электронных микроскопов, ситовой анализ, седиментационные методы.

Энергозатраты при операции измельчения материала определяются в основном его физико-химическими характеристиками, обусловленными напряжением упругих деформаций $\sigma_{\partial}$ и разрушающим $\sigma_{p}$ а также модулем упругости $E$ [7]. Для объектов одного химического состава эти параметры могут отличаться, что определяется их структурным различием и варьированием элементного и компонентного соотношения, то есть показатели находятся прямыми или косвенными методами.

Энергозатраты [8] при измельчении пропорциональны дополнительной поверхности, и для формирования ее единицы необходимо провести удельную работу $a$, величина которой находится эмпирически [9]. Полезная работа измельчителя $W$ увязана с ростом суммы поверхностей частиц $\Delta S$

$$
W=\Delta S \cdot a \text {. }
$$

При сферической форме частиц имеем величину зависимости отношения $S$ и объема частиц $V$ от их среднего диаметра $d$, м

$$
S / V=6 / d
$$

Принимая во внимание (1) и (2), $W$ для измельчения твердого материала, состоящего из частиц с объемом от их начального $d_{u}$ до заданного $d_{\kappa}$, можно вычислить по выражению

$$
W=6 a V\left(\frac{1}{d_{\kappa}}-\frac{1}{d_{\mu}}\right),
$$

а полезную мощность $N_{\text {пол }}$ на переработку массового расхода $G$ потока суспензии с массовой концентрацией дисперсной фазы $x$ рассчитываем по уравнению

$$
N_{\text {пол }}=\frac{6 G x a}{\rho_{u}}\left(\frac{1}{d_{\kappa}}-\frac{1}{d_{н}}\right) \text {, }
$$

где $\rho_{u}$ - плотность дисперсной фазы, кг/м³.

Затрачиваемая электрическая мощность $N$ в этом случае равна

$$
N=\frac{N_{\text {пол }}}{\eta}
$$

где $\eta$ - КПД измельчителя; $\eta$ находится в зависимости от КПД каждой стадии трансформации мощности и равна

$$
\eta=\eta_{\text {кав }} \cdot \eta_{\text {ген }} \cdot \eta_{n p}
$$

где $\eta_{\text {кав }}, \eta_{\text {ген }}$ и $\eta_{n p}$ - КПД кавитации при измельчении, ультразвукового генератора и преобразователя соответственно. $\eta_{\text {ген }}$ и $\eta_{n p}$ можно найти в техническом паспорте, как правило, они не больше $50 \div 60 \%$. $\eta_{\text {кав }}$ обусловлен физико-химическими характеристиками объекта обработки, размерами и формой измельчаемых частиц, длительностью операции диспергирования. В работе [9] определена энергоэффрективность кавитации при диспергировании твердообразного растительного продукта, откуда видно, что $\eta_{\text {кав }}$ при начале операции максимален (в диапазоне $30 \div 40 \%$ ) и впоследствии экспоненциально снижается. 


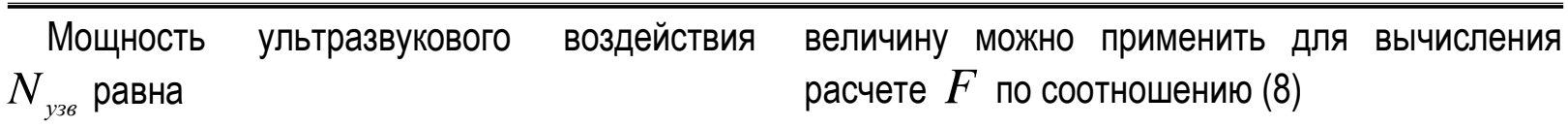

$$
N_{\text {узв }}=N_{\text {пол }} / \eta_{\text {кав }}
$$

опираясь на значение которой вычисляется площадь поверхности излучения $F$

$$
F=N_{y 38} / I
$$

Интенсивность ультразвукового воздействия I оказывает нелинейное влияние на эффективность кавитации при диспергировании и обусловлена частотой колебаний $f$ и амплитудой A

$$
I=0,5 \rho c(2 \pi f A)^{2}
$$

где $\rho=1000$ - плотность обрабатываемой среды (воды), кг/м; $c=1500$ - скорость распространения звука в воде, $\mathrm{M} / \mathrm{c}$.

Рациональные величины $f$ и $A$, обусловливающие максимум эфффективности кавитации, можно определить из критерия эрозийной активности $\chi$. В [10] приведены уровни $\chi$ при варьировании величин $f$ и $A$, причем здесь же сделан вывод о том, что присутствует некоторая линейка рациональных показателей при наибольшей величине $\chi_{\max } \approx 1,29 \cdot 10^{6}$, которая с приемлемой погрешностью описывается регрессионным уравнением

$$
A_{\text {onm }}=6,538 \cdot 10^{-2} / f
$$

где $A_{\text {onm }}$ - рациональная величина $A$ при заданной $f$.

Подставив соотношение (10) в выражение (9), имеем уравнение для расчета рациональной интенсивности ультразвукового воздействия при максимальном кавитационном эффректе. К примеру, для воды при $20^{\circ} \mathrm{C}$ в частотном интервале $22 \pm 1,65 \kappa Г ц ~ I_{\text {опm }}=126,1 \mathrm{kBт} / \mathrm{m}^{2}$. Эту

$$
A_{\text {onm }}=0,00297 \mathrm{~m} ; /=126,1 \mathrm{kBT} / \mathrm{M}^{2} .
$$

Для измельчителя рабочий объем $V_{\text {раб }}$ определяем по уравнению

$$
V_{\text {раб }}=F \cdot H
$$

где $H$ - уровень жидкой среды в измельчителе, м.

Высота жидкостного слоя в установке $H$ обусловлена формированием кавитационного слоя. Эмпирически определено [10], что максимальная активность пузырьковой кавитации в водной фазе образуется в слое, расположенном

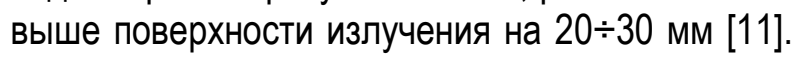
То есть $H$ в измельчителе принимаем более $0,03 \mathrm{M}$.

Результаты и их обсуждение. В качестве эквивалентного диаметра измельченной частицы листьев шпината $d_{\text {экв }}$ целесообразно выбрать диаметр сферы с такой же площадью поверхности. Данный выбор обоснован тем, что размер экстрагируемых частиц и их суммарная площадь поверхности являются важнейшими факторами при интенсификации процесса экстракции. Следует отметить, что размер частицы без учета ее структуры не обязательно является рациональным.

Вследствие того, что ширина и длина значительно превышают толщину частицы, ее можно уподобить бесконечной пластине, где торцевую площадь при моделировании теплопереноса можно не учитывать, однако в реальности при определенном увеличении степени измельчения толщина частиц становится сопоставима с другими размерами, что приводит к увеличению площади контакта фаз. Ввиду неправильной геометрической формы поверхности измельченных частиц в качестве характерного размера $d_{x a p}$ можно принять диаметр круга с площадью, равной ее площади. Таким образом, площадь при контакте фраз можно представить в виде суммы равнозначных поверхностей частиц за исключением торцевой, а при схематичной иллюстрации фотографии представить частицы в 
виде окружностей. В итоге эквивалентный диаметр измельченной частицы листьев шпината можно при массообмене рассчитать из следующего выражения:

$$
d_{\text {экв }}=\frac{d_{x a p}}{\sqrt{2}} .
$$

На рисунке 2 представлены фотографии фррагментов частиц листьев шпината до и после ультразвукового воздействия.

На рисунке 3 представлены схематичные иллюстрации фрагментов частиц листьев шпината до и после ультразвукового воздействия с учетом вышеуказанных допущений.

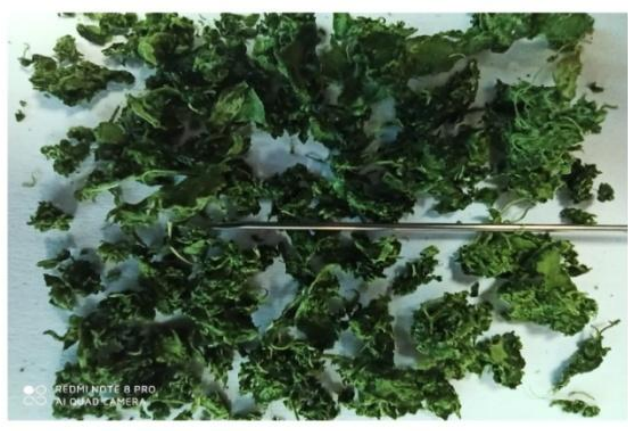

a

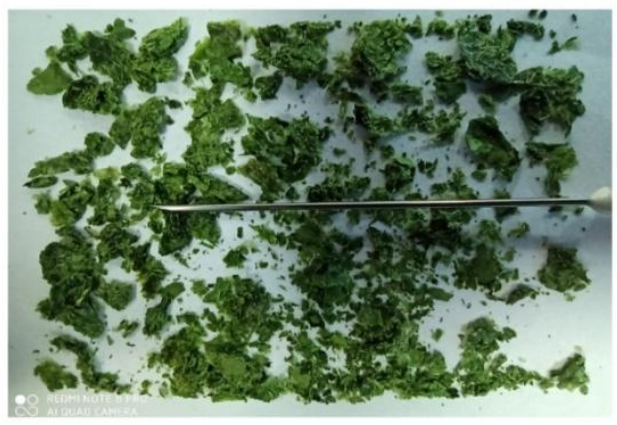

$\sigma$

Puс. 2. Фотографрии фррагментов поверхности измельченных листьев шпината до (а) и после (б) ультразвукового воздействия

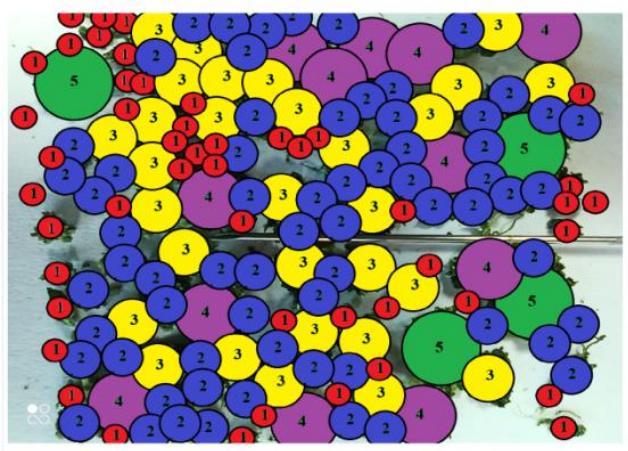

a

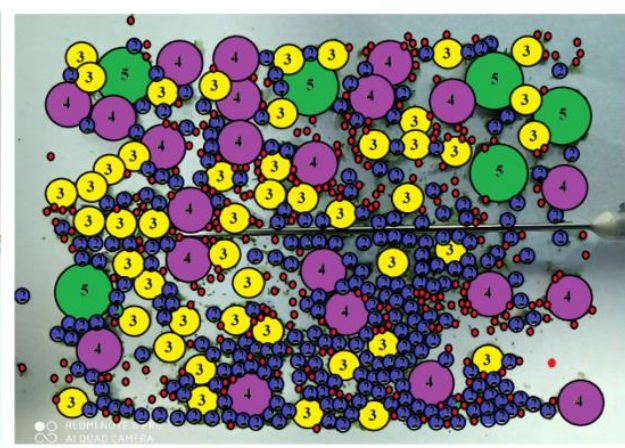

6

Pис. 3. Схематичные иллюстрации фррагментов поверхности измельченных листьев шпината до (а) и после (б) ультразвукового воздействия

Визуальный анализ фотографий показывает присутствие в измельченном материале ориентировочно пяти фрракций, где характерные диаметры частиц в них сравнительно мало отличаются друг от друга, поэтому на схематичной иллюстрации фрагментов (рис. 3) частицы представлены окружностями с их средними диаметрами в каждой фракции, что упрощает математическое описание гранулометрического состава исследуемых материалов.

Полученные эмпирические данные для наглядности и упрощения последующего их анализа, из которого видно, что основная масса измельченных частиц листьев шпината после ультразвукового воздействия находится в диапазоне от 0,5 $\div 1,05 \mathrm{~mm}$, представлены в виде обобщенных гистограмм (рис. 4 и 5). Исходя из второй гистограммы, можно выделить две фракции с частицами, близкими по размеру и относительному содержанию (рис. 6), поэтому с достаточной для инженерных расчетов точностью за размер, характеризующий дисперсную систему, можно принять среднее арифметическое значение между приведенными размерами фрракционных частиц. Сравнительный анализ гистограмм до (рис. 4) и после (рис. 5) измельчения показывает большее количество превалирующих фрракций (три), сравнимых по содержанию в первом случае, что свидетельствует о повышении степени равномерности дисперсного состава после ультразвукового измельчения. 
Параметры, характеризующие дисперсный состав объекта исследования

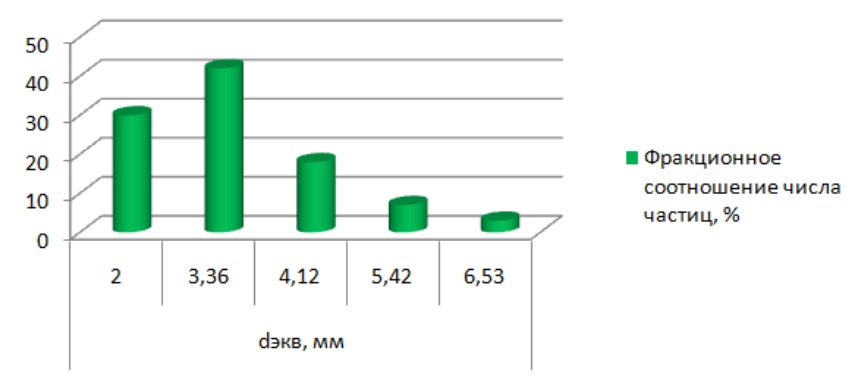

Puc. 4. Дисперсный состав измельченных частиц шпината до ультразвукового воздействия

Параметры, характеризующие дисперсный состав объекта исследования

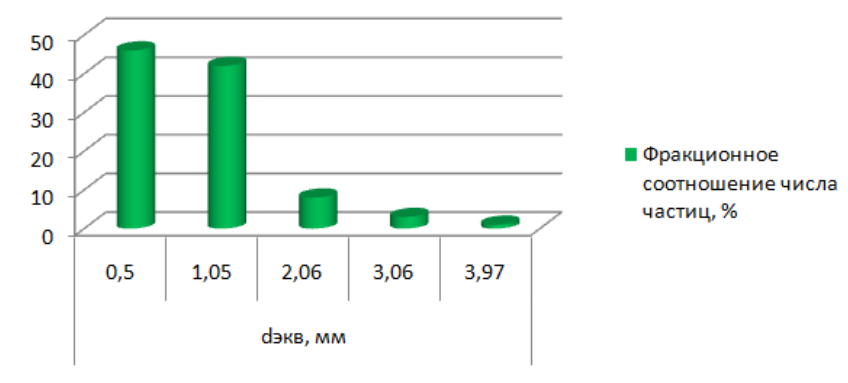

Puc. 5. Дисперсный состав измельченных частиц шпината после ультразвукового воздействия

Таким образом, приведенным размером частички шпината, характеризующим дисперсный состав системы до обработки $d_{н}$ (мм), можно считать среднеарифметическое значение трех основных фрракционных размерных параметров $(2 ; 3,36 ; 4,12)$.

Приведенным размером частички, характеризующим дисперсный состав системы после обработки $d_{\kappa}$ (мм), можно считать среднеарифметическое значение двух основных фракционных размерных параметров $(0,5 ; 1,05)$. В этом случае степень ультразвукового измельчения $i_{y .6 .}=d_{H} / d_{k}=4$.

Для различных видов растительного сырья существует определенный рациональный размер частиц, ниже которого измельчать материал нежелательно. Согласно официально опубликованным статьям Государственной фрармакопеи Российской Федерации [12], растительное сырье должно быть измельчено до требуемых рациональных размеров. Рекомендуемым для растительного сырья считается измельчение

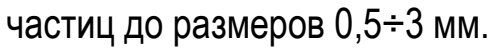

Дисперсный анализ показал, что конечный размер диспергированных ультразвуком частиц листьев шпината $d_{\kappa}$ попадает в требуемый диапазон. Степень измельчения следует оценивать в совокупности с другими фракторами (движущей силой и температурным режимом), что позволит интенсифицировать процесс экстракции хлорофилла из растительного сырья.

Для реализации процесса замачивания и повышения дисперсности растительных частиц листьев шпината при ультразвуковом воздействии можно рекомендовать известную конструкцию ультразвукового диспергатора [13], которая схематично представлена на рисунке 6 .

Экспериментальные исследования показали, что на ультразвуковое измельчение 0,07 кг листьев шпината было затрачено 43200 Дж энергии. Данная масса шпината при ее плотности, равной $1031 \mathrm{kr} / \mathrm{M}^{3}$, занимает объем $6,79 \cdot 10^{-5} \mathrm{M}^{3}$, который в процессе измельчения остается постоянным. 


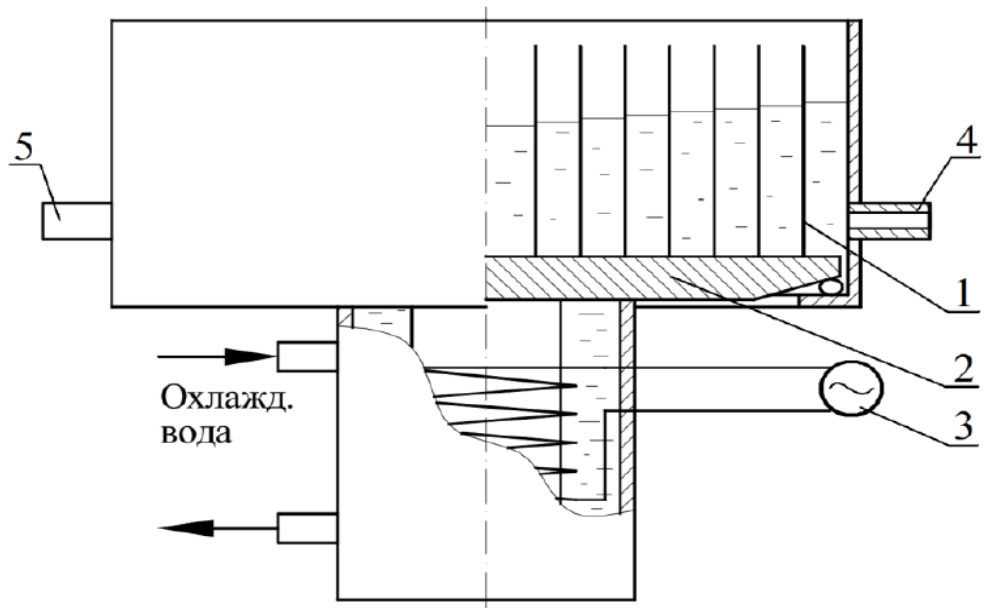

Puc. 6. Схема ультразвукового устройства для замачивания листьев шпината:

1 - пластины; 2 - излучающая поверхность; 3 - генератор колебаний; 4, 5 - входной и выходной патрубки для потока эмульсии

Для расчета $а$ необходимо знать увеличение суммарной поверхности частиц $\Delta S$, которое можно определить следующим образом:

$$
\Delta S=k_{k} S_{k}-k_{H} S_{H},
$$

где $k_{\mu} S_{н}$ и $k_{k} S_{k}$ - суммарная поверхность частиц до и после измельчения, $\mathrm{m}^{2} ; k_{n}$ и $k_{k}-$ количество частиц в объеме до и после измельчения, шт.

$$
\begin{aligned}
k_{u}= & \frac{6 V_{\text {оби }}}{\pi d_{\mu}^{3}}=\frac{6 \cdot 6,79 \cdot 10^{-5}}{3,14 \cdot 0,00316^{3}}=4,11 \cdot 10^{3} \text { шт., } \\
k_{\kappa}= & \frac{6 V_{\text {оби }}}{\pi d_{\kappa}^{3}}=\frac{6 \cdot 6,79 \cdot 10^{-5}}{3,14 \cdot 0,000775^{3}}=2,78 \cdot 10^{5} \text { шт., } \\
& \Delta S=2,78 \cdot 10^{5} \cdot \pi d_{k}^{2}-4,11 \cdot 10^{3} \cdot \pi d_{u}^{2}= \\
= & 0,5243-0,1288=0,3955 \mathrm{~m}^{2}
\end{aligned}
$$

Данный результат получен для измельчения шпината массой 0,07 кг, откуда можно рассчитать удельное увеличение суммарной поверхности частиц $\Delta S_{y \partial}$ (м²/кг), отнесенное к одному килограмму исходного сырья

$$
\Delta S_{y d}=\frac{0,3955}{0,07}=5,65\left(\mathrm{M}^{2} / \mathrm{K} \Gamma\right) .
$$

Тогда затрачиваемая удельная работа $a$ (Дж/м²) на измельчение будет равна

$$
a=\frac{W}{\Delta S}=\frac{43200}{0,3955} \approx 110(\text { КДж/M²). }
$$

Зная величины $\Delta S_{y d}$ и $a$, по формулам (3)(8) и (11) можно рассчитать рабочие параметры промышленной установки для ультразвукового измельчения листьев шпината.

Выводы. Предложена рациональная схема технологического потока подготовки листьев шпината к экстрагированию хлорофилла на основе анализа достоинств и недостатков существующих технологий его получения. Выявлены влияющие на протекание операций подготовки сырья режимные параметры, предложены методы их определения и определены их рациональные величины. Даны практические рекомендации по аппаратурному оформлению технологического потока и реализации результатов исследования.

К примеру, проведенный дисперсный анализ показал, что конечный размер диспергированных ультразвуком частиц листьев шпината попадает в требуемый диапазон. Полученную степень измельчения в ходе проведенного эмпирического исследования следует оценивать в совокупности с другими фракторами (движущей силой и температурным режимом), что дает возможность интенсифицировать процесс экстракции хлорофилла из растительного сырья. 
На основе данных дисперсного анализа, экспериментально полученной величины удельной работы при ультразвуковом измельчении, равной 110 (кДж/ $\left./ \mathrm{M}^{2}\right)$, и известных зависимостей, обусловленных интенсивностью ультразвука, определяемой частотой и амплитудой колебаний излучающей поверхности, получены расчетные фрормулы, используя которые, можно рассчитать рабочие параметры промышленной установки для ультразвукового измельчения листьев шпината.

\section{Литература}

1. А.с. CCCP SU 1450811. Способ сушки шпината: МПК А23В 7/02 / В.Н. Голубев, Л.Н. Пилипенко, С.М. Кобелева, М.А. Гришин, Л.Д. Зеленская. Заявл. 10.10.1985, опубл. 15.01.1989.

2. Roberts J.L., Moreau R. Functional properties of spinach (Spinacia oleracea $L$ ) phytochemicals and bioactives // Food Funct. 2016. 7(8). P. 3337-3353.

3. Хлорофилл А и Б - чем они отличаются [Электронный ресурc]. URL: https: // vchemraznica.ru/xlorofill-a-i-b-chem-oniotlichayutsya/ (дата обращения: 02.12.2019).

4. Akasaka H., Mizushina Y., Yoshida K., Ejima Y., Mukumoto N., Wang T., Inubushi S., Nakayama M., Wakahara Y., Sasaki R. MGDG extracted from spinach enhances the cytotoxicity of radiation in pancreatic cancer cells // Radiat. Oncol. 2016. 11(1). P. 153.

5. Кунавин Г.А., Касторнова А.В. Энергетическая и экономическая эфффективность выращивания шпината // Молодой ученый. 2015. № 6-5. C. 41-43.

6. Левин А.С. Основные принципы анализа размера частиц [Электронный ресурс]. URL: $\quad$ https://www.studmed.ru/levin-asosnovnye-principy-analiza-razmerovchastic_c47b89a557c.html (дата обращения: 17.12.2019).

7. Сиденко П.М. Измельчение в химической промышленности. М.: Химия, 1977. 369 с.

8. Rittinger P.R. Lehrbuch der Aufbereitungskunde. Berlin: Ernst and Korn. 1867. $799 p$.

9. Свиридов Д.П. Оценка энергетической эффективности процесса кавитационного из- мельчения // Известия вузов. Химия и химическая технология. 2009. Т. 52. № 3. C. 103-105.

10. Свиридов Д.П., Семенов И.А., Ситников Д.Н. К расчету ультразвукового диспергатора для измельчения частиц твердого материала в водной среде // Известия вузов. Прикладная химия и биотехнология. 2011. №1. C. 126-129.

11. Свиридов Д.П. Получение устойчивых дисперсных взвесей при помощи кавитации // Современные технологии $и$ научнотехнический прогресс: тез. докл. 2008. № 1. C. 24-28.

12. Определение подлинности, измельченности и содержания примесей в лекарственном растительном сырье и лекарственных растительных препаратах [Электронный pecypc]. URL: http://pharmacopoeia.ru/ofs-15-3-0004-15-opredelenie-podlinnostiizmelchennosti-i-soderzhaniya-primesej-vlekarstvennom-rastitelnom-syre-ilekarstvennyh-rastitelnyh-preparatah/ (дата обращения: 28.12.2019).

13. Патент РФ 2325231. Гомогенизатор ультразвуковой лабиринтный: МПК В02С 19/18, A23L 3/30, B01F 3/12, B01F 3/14 / Д.П. Свиридов, А.А. Кущин, Б.А. Ульянов [и др.]. Заявл. 27.07.2007; опубл. 27.05.2008.

\section{Literatura}

1. A.s. SSSR SU 1450811. Sposob sushki shpinata: MPK A23V 7/02 / V.N. Golubev, L.N. Pilipenko, S.M. Kobeleva, M.A. Grishin, L.D. Zelenskaja. Zajavl. 10.10.1985, opubl. 15.01.1989.

2. Roberts J.L., Moreau R. Functional properties of spinach (Spinacia oleracea $L$ ) phytochemicals and bioactives // Food Funct. 2016. 7(8). P. 3337-3353.

3. Horofill A i B - chem oni otlichajutsja [Jelektronnyj resurs]. URL: https: // vchemraznica.ru/xlorofill-a-i-b-chem-oniotlichayutsya/ (data obrashhenija: 02.12.2019).

4. Akasaka H., Mizushina Y., Yoshida K., Ejima Y., Mukumoto N., Wang T., Inubushi S., Nakayama M., Wakahara Y., Sasaki R. MGDG extracted from spinach enhances the cytotoxicity 
of radiation in pancreatic cancer cells // Radiat. Oncol. 2016. 11(1). P. 153.

5. Kunavin G.A., Kastornova A.V. Jenergeticheskaja i jekonomicheskaja jeffektivnost' vyrashhivanija shpinata /I Molodoj uchenyj. 2015. № 6-5. S. 41-43.

6. Levin A.S. Osnovnye principy analiza razmera chastic [Jelektronnyj resurs]. URL: https://www.studmed.ru/levin-as-osnovnyeprincipy-analiza-razmerovchastic_c47b89a557c.html (data obrashhenija: 17.12.2019).

7. Sidenko P.M. Izmel'chenie $v$ himicheskoj promyshlennosti. M.: Himija, 1977. 369 c.

8. Rittinger P.R. Lehrbuch der Aufbereitungskunde. Berlin: Ernst and Korn. 1867. $799 \mathrm{p}$.

9. Sviridov D.P. Ocenka jenergeticheskoj jeffektivnosti processa kavitacionnogo izmel'chenija // Izvestija vuzov. Himija i himicheskaja tehnologija. 2009. T. 52. № 3. S. 103-105.

10. Sviridov D.P., Semenov I.A., Sitnikov D.N. K raschetu ul'trazvukovogo dispergatora dlja izmel'chenija chastic tverdogo materiala $\mathrm{v}$ vodnoj srede // Izvestija vuzov. Prikladnaja himija i biotehnologija. 2011. №1. S. 126-129.

11. Sviridov D.P. Poluchenie ustojchivyh dispersnyh vzvesej pri pomoshhi kavitacii // Sovremennye tehnologii i nauchnotehnicheskij progress: tez. dokl. 2008. № 1. S. 24-28.

12. Opredelenie podlinnosti, izmel'chennosti i soderzhanija primesej $v$ lekarstvennom rastitel'nom syr'e i lekarstvennyh rastitel'nyh preparatah [Jelektronnyj resurs]. URL: http://pharmacopoeia.ru/ofs-1-5-3-0004-15opredelenie-podlinnosti-izmelchennosti-isoderzhaniya-primesej-v-lekarstvennomrastitelnom-syre-i-lekarstvennyh-rastitelnyhpreparatah/ (data obrashhenija: 28.12.2019).

13. Patent RF 2325231. Gomogenizator ul'trazvukovoj labirintnyj: MPK B02C 19/18, A23L 3/30, B01F 3/12, B01F 3/14 / D.P. Sviridov, A.A. Kushhin, B.A. Ul'janov [i dr.]. Zajavl. 27.07.2007; opubl. 27.05.2008. 